\title{
Prevalence of Risk Factors for Diabetes Mellitus in ANon-Diabetic Population in Jos, Nigeria
}

\author{
${ }^{*}$ Puepet, $\mathrm{F} \mathrm{H}$ ** Ohwovoriole, A E \\ Endocrinology and Metabolic Unit, Department of Medicine, University of Jos "University of Lagos, Nigeria.
}

\begin{abstract}
Background: Diabetes mellitus (DM) is assuming epidemic proportions worldwide, but probably more so in the developing world. Identification of risk factors for the development of type 2 diabetes mellitus is a necessary step in planning prevention programmes for diabetes mellitus. The objective of this study was to determine the frequency of risk factors for type 2DM among inhabitants of Jos, a northern city on the Nigerian Plateau.
\end{abstract}

Method: A district in central Jos was randomly picked. Census of the district was carried out to record the names of all eligible residents from 250 households selected systematically. A questionnaire was administered by trained interviewers. Socio-demographic data, family history of diabetes, and data on work related physical activity were recorded. Height, weight and waist and hip circumferences were also measured. BMI $\left(\mathrm{kg} / \mathrm{m}^{2}\right)$ and waist-hip ration were calculated

Results: Of 902 subjects (= 15years of age), 825 (91.5\%) responded. The mean (SD) age of 400 males and 422 females were respectively 36.4 (15.2) and 39.9 (17.3) years. About $50 \%$ of the respondents were inactive. 435 (52.7\%) were currently taking alcohol. Twenty nine (3.5\%) of the subjects admitted to parental history of DM. 177 (21.4\%) were either overweight or obese. $32 \%$ of males and $86 \%$ of females had abnormal waist circumferences (WCE). 96 (23.8\%) males and 316 (74.9\%) females had abnormal WHR. BMI correlated strongly and significantly with WHR $(r=0.64, p<0.001)$ and WCE $(r=0.72, p<$ 0.001)

Conclusion: Inactivity, alcohol usage and excess weight appear to be dominant risk factors for development of type 2 DM in this group of upland Nigerians.

Key words: Prevalence, risk factors, diabetes mellitus

Date accepted for publication 10th October 2007.

Nig J Med 2008; 71 - 74

copyrightC2008 Nigerian Journal of Medicine

\section{INTRODUCTION}

Diabetes mellitus (DM) is assuming epidemic proportions worldwide, but probably more so in the developing world. The global prevalence of diabetes mellitus has been projected to rise from 155 million in 2000 to 366 million by the year $2030,{ }^{1}$ which translates to an increase of $14.6 \%$ in the developing and only $46 \%$ in developed countries. ${ }^{2,3}$ Thus, the developing world will contribute $77.6 \%$ of the total diabetes burden in the world by the year 2030.

The major risk factors associated with the development of diabetes mellitus are, family history, physical inactivity, obesity and alcohol consumption. Studies of family history of DM in Africans have mostly been on probands with DM ..$^{4-7}$ In Nigeria, Osuntokun et al ${ }^{4}$ in 1971 found $2.4 \%$ positive family history from 832 diabetics. More recently, a study from Jos in 2002 reported positive family history of DM in $23.8 \%$ of 150 diabetic probands and $6 \%$ of 200 non-diabetic controls. 7

Several cross-sectional studies have shown 2 to 4 fold differences in the prevalence of type $2 \mathrm{DM}$ between the least active and the most active individuals. ${ }^{8}$ In Africans, prevalence of DM has been found to be higher among urban sedentary office workers ${ }^{9,10}$ than in active rural farmers. ${ }^{10-12}$ Obesity has been implicated as a risk factor for type 2 DM in cross-sectional and longitudinal studies. ${ }^{9,}{ }^{13-15}$ Body mass index (BMI) is positively associated with increased risk of type $2 \mathrm{DM}$ in both sexes in many ethnic groups. ${ }^{9,13-15}$ In Africans, the BMI has been found to be lower in rural people ${ }^{12,16}$ than in their urban counterparts. ${ }^{9}$ Centralized distribution of body fat (referred to as abdominal or central obesity), determined as waist Circumference (WC) and waisttohip ratio (WHR) has been implicated as a risk for type 2 DM in several ethnic groups. ${ }^{9,13}{ }^{15}$ However, physical training and weight loss in individuals with abdominal obesity leads to improvement in WHR and glucose tolerance. ${ }^{8,17}$

Alcohol consumption has been associated with diabetes mellitus in adult Africans. ${ }^{18,19}$ Excessive alcohol consumption may lead to chronic pancreatitis with calcification and diabetes and some alcoholic drinks taken in certain areas of Southern Africa contain large quantity of iron which may damage the pancreas and lead to diabetes. ${ }^{18,19}$ This phenomenon was observed to be responsible for the high prevalence of pancreatic diabetes among urban immigrant African workers in Zimbabwe. ${ }^{19}$ In Jos Nigeria, Okoye et al, ${ }^{20}$ observed that 
the local inhabitants heavily consumed the native alcoholic drink (Burukutu) brewed in metal pots and drums (which contained large quantity of iron) and aflatoxin $B_{1}$ (in the grains).

Identification of risk factors for the development of type 2 diabetes mellitus is a necessary step in planning prevention programmes for diabetes mellitus. The objective of this study therefore, was to determine the frequency of risk factors for type $2 \mathrm{DM}$ among inhabitants of Jos, a northern city on the Nigerian Plateau

\section{SUBJECTS AND METHODS}

A ward in Giring district in central Jos was picked using a two-stage random cluster sampling scheme based on existing administrative divisions. Census of the ward (Dagip) was carried out to record names of eligible residents from 250 households selected systematically. A total of 902 subjects aged $=15$ years were enrolled for the study. III and pregnant subjects were excluded. All subjects were non-diabetics. A questionnaire was administered by trained interviewers. Socio-demographic data, family history of diabetes, and data on work-related physical activity were recorded. Height, weight and waist and hip Circumferences were also measured. BMI $\left(\mathrm{kg} / \mathrm{m}^{2}\right)$ and waist-to-hip ratio (WHR) were calculated.

Work-related physical activity was separated into 3 grades according to occupation as defined by the National NCD survey ${ }^{(21)}$ : (1) not active (sedentary) e.g office work and unemployment; (2) moderately active e.g. house work, trade work, nursing; and (3) Very active e.g. labouring. Leisure activity was graded as follows:

(1) not active e.g housebound; (2) moderately active e.g gardening, walking and sports 1-2 days/week; and (3) very active e.g. sports $=3$ days/week.

Alcohol drinkers were categorized into: heavy drinkers (> 2 drinks/day during the week and / or $>8$ drinks on the weekend); and light drinkers (occasional drink). ${ }^{19} \mathrm{~A}$ drink was defined as 1 bottle of beer, or a glass of wine or 1 calabash (about $500 \mathrm{ml}$ ) of locally brewed beer).

Weight was recorded to the nearest $0.5 \mathrm{~kg}$ using an electronic scale (subjects without shoes and in fasting state). ${ }^{22}$ Height was recorded in centimeters using a stadiometer (subjects without shoes and head-gear) ${ }^{22}$ Body mass index (BMI) was calculated as weight $(\mathrm{kg})$ divided by the square of height $\left(\mathrm{m}^{2}\right)\left(\mathrm{kg} / \mathrm{m}^{2}\right){ }^{22}$ BMl categories were defined as follows : $<18.5$, underweight, 18.5-24.9 normal, 25 to 29.9 overweight and $=30$ Obese. ${ }^{23}$ Waist and hip Circumferences were measured in centimeters using a non-stretch linear tape with subjects in minimal clothes. Waist circumference (WC) was the horizontal level at the mid point between the iliac crest and the lower costal margin; and hip circumference $(\mathrm{HC})$ was the horizontal level of maximum circumference around the buttocks, i.e. the widest diameter of the hips. ${ }^{22,23}$ Waist circumference of $=102 \mathrm{~cm}$ in males and $=88 \mathrm{~cm}$ in females were abnormal. ${ }^{23}$ Waist- to- hip ratio (WHR) of $=0.90$ in males and 0.85 in females were abnormal. ${ }^{23}$

\section{STATISTICALANALYSIS}

Data were entered in Microsoft Excel $\circledast$ and analyzed using Epi- Info 2000 statistical programme. Means (SD) were used to describe continuous variables and proportions were used for categorical data. Two-tailed student's t- test was used to compare group means, while the $X^{2}$ test was used to compare proportions. Pearson's correlation was used to determine relationship of the risk factors. In all cases $p$ - values < 0.05 were considered significant.

\section{RESULTS}

Of 902 subjects, 825 (91.5\%) responded. The mean (SD) age of 403 males and 422 females were $36.4(15.2)$ and $39.9(17.3)$ years respectively, $p<0.01$. There was no significant difference in the age distribution of males and females, $X^{2}=7.34, p>0.05$.

The level of physical activity of the subjects is shown in Table I. Males appeared more active than females $\left(X^{2}=\right.$ $52.74, p<0.001) .406(49.2 \%)$ of the respondents were inactive.

More than half $(52.7 \%)$ of the respondents were currently taking alcohol. 526 (64\%) of the subjects had a history of alcohol use (Table II); $91(11 \%)$ only stopped drinking less than 1 year before the survey. There was no significant difference in the proportions of the males $(55.1 \%)$ and females $(50.5 \%)$ currently taking alcohol, $X^{2}=2.20, p<0.05$. Amongst the alcohol users, $84.8 \%$ were moderate to heavy drinkers, while only $15.2 \%$ were light drinkers.

Only $29(3.5 \%)$ of the subjects admitted to parental history of DM, of these $13(1.6 \%)$ subjects had diabetic mothers and $16(1.9 \%)$ had diabetic fathers. None of the respondents had history of DM in both parents.

The frequencies of overweight, obesity and abnormal WCE and WHR in the respondents are shown in Table III. More than half of the subjects(53.9) had BMI 
between 18.5 and $24.9 \mathrm{~kg} / \mathrm{m}^{2}$ (normal); while $21.4 \%$ of the subjects, [ $78(19.4 \%)$ males and 99(23.5) females] were either overweight or obese $\left(X^{2}=5.7, p=0.04\right)$. Of these, $35(4.2 \%)$ of the subjects, $16(4.0 \%)$ males and $19(4.5 \%)$ females were obese, $p>0.05$. The relationship between BMI and age was poor and insignificant $(r=0.17, p$ $>0.05$ ). Waist circumference (WCE) were elevated or abnormal in $128(31.8 \%)$ males and $362(85.8 \%)$ females $\left(X^{2}=58.6, p<0.001\right)$. WHR were abnormal in $96(23.8 \%)$ males and $316(74.9 \%)$ females $\left(X^{2}=56.8, p<0.001\right)$. In these respondents $\mathrm{BMI}$ correlated strongly and significantly with WCE $(r=$ $0.72, p<0.001)$ and $W H R(r=0.64, p<0.001)$.

\section{Table I: Level of Physical activity by gender in study subjects}

No. of Subjects (\%)

\begin{tabular}{lccr} 
Level of Activity & Males & Females & \multicolumn{1}{l}{ Total } \\
Very active & $123(30.5)$ & $44(10.4)$ & $167(20.2)$ \\
Moderately active & $114(28.3)$ & $138(32.7)$ & $252(30.6)$ \\
Not active & $166(41.2)$ & $240(56.9)$ & $406(49.2)$ \\
$\quad$ Total & 403 & 422 & 825 \\
& & &
\end{tabular}

Table II Alcohol intake by gender in study subjects

\begin{tabular}{llcl}
\multicolumn{4}{l}{ No. of Subjects (\%) } \\
Alcohol Intake & Males & Females & Total \\
Yes & $222(51.1)$ & $213(50.5)$ & $435(52.7)$ \\
Stopped & $45(11.2)$ & $46(10.9)$ & $91(11.0)$ \\
Never & $136(33.7)$ & $163(38.6)$ & $299(36.2)$ \\
Total & 403 & 422 & 825 \\
& & &
\end{tabular}

Table III: Frequencies of overweight and indices of obesity by gender in study subjects

\begin{tabular}{|c|c|c|c|}
\hline Parameter & Males(\%) & Females( $\%)$ & Statistics \\
\hline $\begin{array}{l}\text { Frequency of } \\
\text { Overweight }\end{array}$ & $62(15.4)$ & $80(19.0)$ & $X^{2}=4.21, p=0.07$ \\
\hline $\begin{array}{l}\text { Frequency of } \\
\text { Obesity }\end{array}$ & $16(4.0)$ & $19(4.5)$ & $X^{2}=2.11, p>0.05$ \\
\hline Elevated WC & $128(31.8)$ & $362(85.8)$ & $X^{2}=58.6,{ }^{*} p<0.001$ \\
\hline Elevated WHR & $96(23.8)$ & $316(74.9)$ & $x^{2}=56.8,{ }^{*} p<0.001$ \\
\hline
\end{tabular}

${ }^{*} \mathrm{P}<0.05$, statistically significant.

\section{DISCUSSION}

Identification of risk factors for the development of type 2 diabetes mellitus is a necessary step in planning prevention programmes for diabetes mellitus. Risk factors for diabetes have always been studied in probands and relations of people with diabetes mellitus. It is essential to identify these risk factors in the general non-diabetic population. This study describes the frequency of common risk factors for the development of type 2 DM in an urban non-diabetic population in the North central city of Jos.

In relation to gender, the study population had fairly equal distribution and similar age. In this study almost half $(49.2 \%)$ of the population were inactive. The risk for developing type $2 \mathrm{DM}$ has been shown to increase 2-to4 fold in inactive individuals. ${ }^{8}{ }^{10}$ Increasing the level of physical activity leads to improvement in glucose tolerance. ${ }^{8,17}$

The frequency of alcohol consumption in quite high in this population $(64 \%)$ and there was no significant gender difference in distribution of alcohol users and teetotalers. These findings is similar to those of Wicks et al ${ }^{18,19}$ in Zimbabwe who reported a frequency of alcohol consumption of about $50 \%$ in a Zimbabwean population with a high prevalence of diabetes mellitus. They even postulated that alcohol may be solely responsible for the high prevalence of DM in the urban community. Education and counseling about the risk of excessive alcohol consumption is required in this situation.

The Prevalence of overweight and obesity (21.4\%) was moderately high although not as high as those of black South Africans (35\%) and Australian Aboriginal communities. Considering BMl standards alone is not as strong an indicator of cardiovascular and DM risk as other anthropometric measures of obesity and adiposity, and use of constant BMI standards in classifying individuals may be faulty. ${ }^{8,9,23}$ Other indices that are reportedly more closely correlated with $\mathrm{DM}$ and cardiovascular risk were also utilized in this study. ${ }^{9}$ The measurements of waist and Hip circumferences (WC and $\mathrm{HC}$ ) are invaluable in our environment because of the relative ease of measurement, economy, convenience and availability.

The proportions of our subjects with elevated WC and WHR were significantly higher than the proportion with abnormal BMI, and prevalence of these abnormal indices in females more than doubled that in males. 
There were no significant differences in the proportions of males and females with BMI in the overweight or Obese ranges. Studies in black South Africans ${ }^{9}$ and Australian Aborigines ${ }^{13}$ observed similar trends; prevalence of obesity being higher in females than in males when truncal or abdominal obesity (elevated WC and WHR) were considered. Several studies have suggested that preventing obesity may be important in reducing the development of type $2 \mathrm{DM} .{ }^{13,17}$ The prevention of obesity on the long- term may require very early interventional strategies such as regular physical exercise instituted in childhood and adolescence. ${ }^{15,17}$

Family history of diabetes was scanty in the studied population. This may suggest that genetics may not be an important risk factor for DM in this population. Scanty family history of DM has been reported even among probands of DM by Osuntokun et al (4) in Ibadan, Nigeria. The remarked that ignorance about diabetes and the fact

\section{REFERENCES}

1. Wild S, Roglie G, Green A, Sicree R, King H. Global prevalence of Diabetes. Diabetes Care 2004; 27(s): 1047-1053.

2. Amos AF, McCaity DJ, Zimmet P. The rising global burden of diabetes and its complications. Estimates and projections to the year 2010. Diabetes Med. 1997; 14(Suppl 5): 1-85.

3. King $\mathrm{H}$, Aubert RE, Herman WH. Global burden of diabetes 1995-2005 prevalence. Numerical estimates and projections. Diabetes Care 1998; $21: 1414-1431$.

4. Osuntokun BO, Akinkugbe FM, Francis TT, Reddy S, Taylor GOL. Diabetes mellitus in Nigeria. A study of 832 patients. West Afr Med J 1971; 20: 295-312.

5. Omar M, Asmal AC. Family histories of diabetes mellitus in young African and Indian diabetics BMJ 1983; 286: 1786-1789.

6. Mengesha B, Abdulkadir J, Oli k, Lugi y. Study of family history among parents and siblings of Ethiopian diabetics: a preliminary report. J Trop Med and Hyg 1990; 93: 39-41.

7. PuepetFH, Chuhwak EK. Study of Family history among parents and siblings of Nigerian diabetics in Jos: A preliminary report. Journal of Medicine in the Tropics 2002; 4: 6-9

8. WHO Study Group. Prevention of Diabetes mellitus. Geneva, World Health Organization, 1994 WHO Technical Report series No. 844.

9. Levith NS, Katzenellenbogen JM, Bradshaw D, Hoffman MN, Bonnici $F$. The prevalence and identification of risk factors for NIDDM in urban Africans in Cape Town, South Africa. Diabetes Care, 1993; 16: 601-607

10. Imperato PJ, Handelsman MB, Fafana B, Sow O. The prevalence of diabetes mellitus in three population groups in the Republic of Mali. Trans Royal Soc Trop Med and Hyg 1976; 70 (2): 155-158

11. Teuscher T, Rosman JB, Bailled P, Teuscher A. Absence of diabetes in a rural West African population with a high carbohydrate/cassava diet. Lancet 1987; $i$ : 765-768.

12. McLarthy DG, Swai ABM, Kitange HM, Masuki G, Mtinagi BL, Alberti KGMM. Prevalence of Diabetes and IGT in rural Tanzania. The Lancet 1989 ; i : 871-875. that Africans are usually reluctant to reveal family history of illnesses may be responsible for the scanty family history of diabetes.

Inactivity, alcohol usage and overweight and obesity (particularly abdominal obesity) appear to be dominant risk factors for type $2 \mathrm{DM}$ in this group of upland Nigerians. The findings of our study are by no means novel, but serve to emphasize the occurrence of these risk factors (particularly obesity in black females), which are potentially modifiable. Life style modification to reduce the occurrence of these risk factors and hence reduce the development of type 2 diabetes mellitus forms the basis for primary prevention of type $2 \mathrm{DM} .{ }^{8} \mathrm{We}$ advocate that individuals identified with risk factors for type 2 DM should be targeted for intervention programmes to reduce the rate of development of diabetes mellitus.

13. O'Dea K, Patel M, Kubisch RN, Hopper J, Traisnede MS. Obesity, Diabetes and Hyperlipidaemia in a Central Australian Aboriginal community with a long history of acculturation. Diabetes Care 1993; 16 : 1004- 1010.

14. Collins VR, Dowse GK, Aloaina FL. Spark RA, Toelupe PM et al Increasing prevalence of NIDDM in the pacific island population of Western Samoa over a 13 year period. Diabetes Care 1994; 17: 288-296.

15. Shaten J, Smith GD, Kuller LH, Neaton JD. Risk factors for the development of Type 2 Diabetes among men enrolled in the usual care group of the multiple risk factor intervention trial. Diabetes care 1993; 16: 1331-1339.

16. Fisch A, Pichard E, Prazuck T, Leblanc H, Sidibe Y, Brucker G. Prevalence and risk factors of diabetes mellitus in rural region of Mali: a practical approach. Diabetologia 1987; 30: 859-862.

17. Helmrich SP, Ragland DR, Leung RW, Paffenbarger RS. Physical activity and reduced occurrence of NIDDM. N Engl J Med. 1991;325: 147-151.

18. Wicks ACB, Castle WM, Gelfand M. Effect of time on the prevalence of diabetes in the urban African of Rhodesia. Diabetes 1973; 22: 733-737.

19. Wicks ACB, Lowe RF, Jones JJ. Alcohol a cause of diabetes in Rhodesia. South Afr Med J 1974; 48: 1115 -1117.

20. Okoye $\mathrm{C}$, Ekpenyoung $\mathrm{KI}$. Aflatoxin $\mathrm{B}_{1}$ in native millet beer brewed in Jos and Surbubs. Trans Royal Soc Trop Med Hyg 1984; 78: 417-418.

21. National Expert committee on Non- communicable Disease (NCD) in Nigeria. Ed. Akinkugbe 00. Report of a National survey 1997.

22. Dowse GK, Zimmet P. A model protocol for a diabetes and other non-communicable disease field survey. World Health Statistics Quarterly 1992; 45: 360-372.

23. National Institute of Health: National Heart, Lung and Blood Institutes. Clinical guidelines on the identification, evaluation and treatment of overweight and obesity in adults; the evidence report. Obes Res 1998 ; 6 (suppl 2) :515- 2095. 